\title{
Aspectos morfofisiológicos na pré-aclimatização in vitro e aclimatização de plantas de caroá ${ }^{1}$
}

\author{
Morpho-physiological aspects of in vitro pre-acclimatization and acclimatization of \\ the caroá plant
}

\author{
Daniela Garcia Silveira ${ }^{2 *}$, Ádila Melo Vidal ${ }^{2}$, Carlos Alberto da Silva Ledo ${ }^{3}$, José Raniere Ferreira de Santana ${ }^{4}$ e \\ Fernanda Vidigal Duarte Souza $^{3}$
}

\begin{abstract}
RESUMO - $O$ objetivo deste trabalho foi estudar a influência da sacarose $\left(0 ; 15\right.$ e $\left.30 \mathrm{~g} \mathrm{~L}^{-1}\right)$, tipo de vedação (filme de PVC e tampão de algodão) dos tubos de ensaio, e a concentração dos sais do meio MS (50; 75 e 100\%) sobre os aspectos morfofisiológicos das plantas de caroá durante a fase de pré-aclimatização in vitro visando otimizar a taxa de sobrevivência e reduzir o tempo de aclimatização das mudas. A análise das características de comprimento, produção de matéria seca, taxa de sobrevivência e enraizamento mostraram que as plantas de Neoglaziovia variegata nas fases de pré-aclimatização in vitro e aclimatização foram dependentes das concentrações de sacarose e nutrientes inorgânicos, além da aeração. Melhores resultados foram obtidos quando as mudas de caroá foram inoculadas em meio MS com a concentração original dos sais do MS, suplementado com 15 ou $30 \mathrm{~g} \mathrm{~L}^{-1}$ de sacarose e vedadas com tampão de algodão.
\end{abstract}

Palavras-chave: Caroá. Tecidos vegetais-cultura e meios de cultura. Sacarose.

\begin{abstract}
This work aimed to evaluate the influence of sucrose $\left(0 ; 15\right.$ and $\left.30 \mathrm{~g} \mathrm{~L}^{-1}\right)$, the type of seal used in the test tubes (PVC film or cotton plug), and salt concentration in the MS medium (50\%; 75\% and 100\%) on the morphological and physiological traits of caroá plants during in vitro pre-acclimatization phase aiming to optimize the survival rate and shorten the acclimatization period of the seedlings. The analysis of characteristics such as length, dry matter production, survival rate and rooting, showed that Neoglaziovia variegata plants at pre-acclimatization and acclimatization stages were dependent on sucrose concentrations, inorganic nutrients from MS medium and aeration. The best results in the acclimatization stage were obtained when the caroá seedlings were inoculated in MS medium with the full salt concentration, supplemented with 15 or $30 \mathrm{~g} \mathrm{~L}^{-1}$ sucrose, and sealed with cotton plugs during the pre-acclimatization stage.
\end{abstract}

Key words: Caroá. Plant tissue-culture and culture medium. Sucrose.

\footnotetext{
* Autor para correspondência

${ }^{1}$ Recebido para publicação em 03/11/2011; aprovado em 08/01/2013

Pesquisa financiada pelo Banco do Nordeste

${ }^{2}$ Programa de Pós-Graduação em Ciências Agrárias, Centro de Ciências Agrárias, Ambientais e Biológicas, Universidade Federal do Recôncavo da Bahia/UFRB, Cruz das Almas-BA, Brasil, 44.380-000, danielags@ig.com.br, amelovidal@yahoo.com.br

${ }^{3}$ Embrapa Mandioca e Fruticultura, Cruz das Almas-BA, Brasil, 44.380-000, ledo@cnpmf.embrapa.br, fernanda@cnpmf.embrapa.br

${ }^{4}$ Unidade Experimental Horto Florestal, Universidade Estadual de Feira de Santana, Feira de Santana-BA, Brasil, 44.055-000, raniere@gmail.com
} 


\section{INTRODUÇÃO}

Neoglaziovia variegata (Arruda) Mez, conhecida como caroá, pertence à família Bromeliaceae, e é uma planta com elevada importância no cenário econômico, social e ecológico do Semiárido do Nordeste Brasileiro. Isto se deve ao fato de que suas fibras já foram muito utilizadas nas indústrias têxteis na primeira metade do século passado e recentemente voltaram a ser uma das principais fontes de emprego e renda para diversas famílias nordestinas com a fabricação de produtos artesanais (SILVEIRA et al., 2009a). Contudo, a coleta das plantas para a extração das fibras sempre ocorreu de forma extrativista colocando a sobrevivência da espécie em condição de ameaçada em algumas regiões nordestinas.

A propagação do caroá ocorre por sementes e pelo desenvolvimento de gemas e rizomas laterais, mas possui taxa de multiplicação baixa, o que se constitui em uma limitação para a produção de mudas, e consequentemente para o estabelecimento de cultivos racionais (SILVEIRA et al., 2009b). Dessa maneira, a cultura de tecidos, com suas variadas técnicas, apresenta-se como uma ferramenta relevante no estabelecimento de protocolos de micropropagação para broméliáceas seja por organogênese ou embriogênese somática (POMPELLI; FERNANDES; GUERRA, 2005; POMPELLI; GUERRA, 2004).

Estudos in vitro com essa espécie vêm sendo realizados desde 2005 visando desenvolver um protocolo de micropropagação para obtenção de mudas sadias, possibilitando o estabelecimento de um sistema racional de cultivo e produção com vistas a minimizar o extrativismo predatório. Esse protocolo, já obtido com êxito, foi possível a partir do uso de plântulas germinadas in vitro e de uma série de ensaios realizados para a adequação das melhores condições de seu cultivo in vitro (SILVEIRA et al., 2009b). No entanto, a etapa da aclimatização, onde ocorre a transferência das plantas para condições externas ao laboratório (ex vitro) pode ser limitante para algumas espécies. Neste momento ocorre a transição do heterotrofismo para o autotrofismo, havendo um número expressivo de espécies vegetais micropropagadas que não sobrevive nesse período (HARARIKA, 2003), devido ao sistema radicular adventício produzido in vitro ser, em geral, pouco ramificado, quebradiço e isento de pêlos radiculares, com raízes pouco funcionais na absorção de água e nutrientes durante a aclimatização (HOFFMANN et al., 2001). No que se refere às bromeliáceas as taxas de sobrevivência são elevadas, mas o longo tempo de aclimatização é um fator a ser considerado para a melhoria de todo o processo (SOUZA et al., 2009).

No caso do caroá, Silveira et al. (2010) aclimatizaram diretamente brotos e plantas (sem passar pela etapa de enraizamento in vitro) em diversos substratos, tendo obtido os melhores resultados nos substratos comerciais Ecoterra $^{\circledR}$ e Plantmax ${ }^{\circledR}$. No entanto, o tempo de aclimatização registrado de 210 dias é considerado demasiadamente longo, demandando ainda novos ajustes.

Uma das alternativas para reduzir o tempo de aclimatização é a passagem das plantas por um período de rustificação ou pré-aclimatização, que consiste em mudanças no ambiente in vitro para estimular a transição de heterotrofismo para o autotrofismo. Em vista disso vários estudos e trabalhos vêm sendo desenvolvidos com o intuito de minimizar os danos causados pela transição de uma condição à outra (CHANDRA et al., 2010; JACKSON, 2003). Souza et al. (2006) sugerem a pré-adaptação à condição autotrófica mediante redução da concentração de sacarose no meio de cultura, para promover a rustificação in vitro, buscando aumentar a capacidade fotossintética das plantas. A concentração elevada de sais do MS pode prejudicar o enraizamento de brotos em algumas espécies, o que tem levado alguns pesquisadores a trabalhar com diluições das formulações básicas deste meio (ERIG; SCHUCH; HAVES, 2004; OLIVEIRA et al., 2010; RIBEIRO et al., 2008). Outro fator que merece destaque é a aeração dos recipientes de cultivo. A condição de esterilização necessária aos cultivos in vitro e a manutenção do ambiente asséptico no interior dos frascos de cultivo impõe um selamento severo dos recipientes, impedindo dessa forma trocas gasosas, tão necessárias ao bom desenvolvimento das plantas (JACKSON, 2003). Buscando minimizar essa ausência total de trocas gasosas, vários autores vêm trabalhando nesta direção considerando, principalmente, os recipientes a serem usados assim como a forma de vedação (SILVA et al., 2005). Segundo Santana et al. (2008) o fechamento dos tubos com tampa plástica sem PVC ou com tampão de algodão permite as trocas gasosas com o ambiente externo, estimula a mudança do modo de crescimento heterotrófico para fotaoutotrófico durante a fase de enraizamento, facilitando e diminuindo o tempo de aclimatização.

Sendo assim, este trabalho teve como objetivo avaliar as respostas morfofisiológicas das plantas micropropagadas de caroá [Neoglaziovia variegata (Arruda) Mez] nas fases da pré-aclimatização e aclimatização, visando otimizar a produção de mudas dessa espécie.

\section{MATERIAL E MÉTODOS}

\section{Material vegetal e condições de cultivo in vitro}

Foram utilizadas plantas de caroá provenientes do quinto subcultivo em meio MS (MURASHIGE; SKOOG, 1962) suplementado com $0,5 \mu \mathrm{M}$ de ANA (ácido 
naftalenoacético) $+2,2 \mu \mathrm{M}$ de CIN (cinetina). As plantas apresentavam sistema radicular desenvolvido durante a etapa de multiplicação. Contudo, as raízes foram eliminadas, limpando-se a base das plantas antes de serem introduzidas nos diferentes meios de cultura solidificados com $2 \mathrm{~g} \mathrm{~L}^{-1}$ de Phytagel $^{\circledR}, \mathrm{pH}$ ajustado para 5,8 antes da autoclavagem.

Com essas plantas instalaram-se dois experimentos de pré-aclimatização in vitro e as plantas obtidas do segundo experimento foram usadas para o ensaio de aclimatização. Em todos os experimentos realizados nas condições in vitro, as culturas foram mantidas em sala de crescimento com temperatura de $27 \pm 1{ }^{\circ} \mathrm{C}$, sob fotoperíodo de 16 horas e densidade de fluxo de fótons de $22 \mu \mathrm{molm}^{-2} \mathrm{~s}^{-1}$.

\section{Experimento 1: Influência da sacarose e do tipo de fechamento dos tubos de ensaio}

As plantas foram inoculadas (estabelecidas in vitro) em tubos de ensaio contendo meio de cultura MS suplementado com diferentes concentrações de sacarose $\left(0 ; 15\right.$ e $\left.30 \mathrm{~g} \mathrm{~L}^{-1}\right)$ e vedados com filme de PVC e tampão de algodão.

O delineamento experimental foi inteiramente casualizado, em esquema fatorial $3 \times 2$ (concentrações de sacarose e tipos de fechamento dos tubos) com 10 repetições por tratamento, sendo cada repetição uma planta por tubo.

\section{Experimento 2: Influência da sacarose e dos sais do MS}

Neste experimento, as plantas foram transferidas para tubos de ensaio contendo meio MS com diferentes concentrações dos sais $(50 ; 75$ e $100 \%$ da concentração original) e de sacarose $\left(0 ; 15\right.$ e $\left.30 \mathrm{~g} \mathrm{~L}^{-1}\right)$. Com base nos resultados do experimento anterior, utilizou-se o tipo de fechamento dos tubos de ensaio com tampão de algodão.

O delineamento experimental utilizado foi $\mathrm{o}$ inteiramente casualizado, em esquema fatorial $3 \times 3$ (concentrações de sais do MS e concentrações de sacarose) com 10 repetições por tratamento, sendo cada repetição uma planta por tubo.

\section{Experimento 3: Aclimatização das plantas de caroá}

As plantas obtidas do experimento anterior foram transplantadas para tubetes contendo o substrato comercial Plantmax ${ }^{\circledR}$ e mantidas em estufa sob nebulização.

O delineamento experimental utilizado foi $\mathrm{o}$ inteiramente casualizado, em esquema fatorial $3 \times 3$ (concentrações de sais do MS e concentrações de sacarose), com 10 repetições por tratamento, sendo cada repetição uma planta por tubete.

\section{Variáveis analisadas e análise estatística}

Para os dois primeiros experimentos, avaliou-se aos 30 dias de cultivo in vitro, as seguintes variáveis: taxa de enraizamento (\%), o número de folhas, o comprimento (cm) da parte aérea e o número de raízes.

No experimento de aclimatização foi avaliado aos 180 dias a taxa de sobrevivência (\%), o número de folhas, o comprimento da parte aérea $(\mathrm{cm})$, o número de raízes e as matérias secas da parte aérea e das raízes (g).

Para as variáveis, número de folhas e número de raízes foi realizada a transformação raiz quadrada visando o atendimento das pressuposições da análise de variância. Os dados foram submetidos à análise de variância e as médias dos tratamentos foram comparadas pelo teste de Tukey a 5\% de significância. As análises estatísticas foram realizadas pelo programa estatístico SAS.

\section{RESULTADOS E DISCUSSÃO}

Na Figura 1 observa-se que, no experimento entre as concentrações de sacarose e tipos de vedamento dos tubos de ensaio, houve ocorrência de enraizamento em todos os tratamentos, mesmo naqueles que não havia suprimento de carbono no meio de cultura. Os maiores percentuais de plantas enraizadas in vitro foram provenientes do cultivo em tubos vedados com tampas de algodão.

O resumo da análise de variância realizada para número de folhas $(\mathrm{NF})$, comprimento $(\mathrm{cm})$ da parte aérea (CPA) e número de raízes (NR) de plantas de caroá após 30 dias de pré-aclimatização in vitro para o

Figura 1 - Enraizamento in vitro (\%) de plantas micropropagadas de caroá [N. variegata (Arruda) Mez] após 30 dias de préaclimatização in vitro

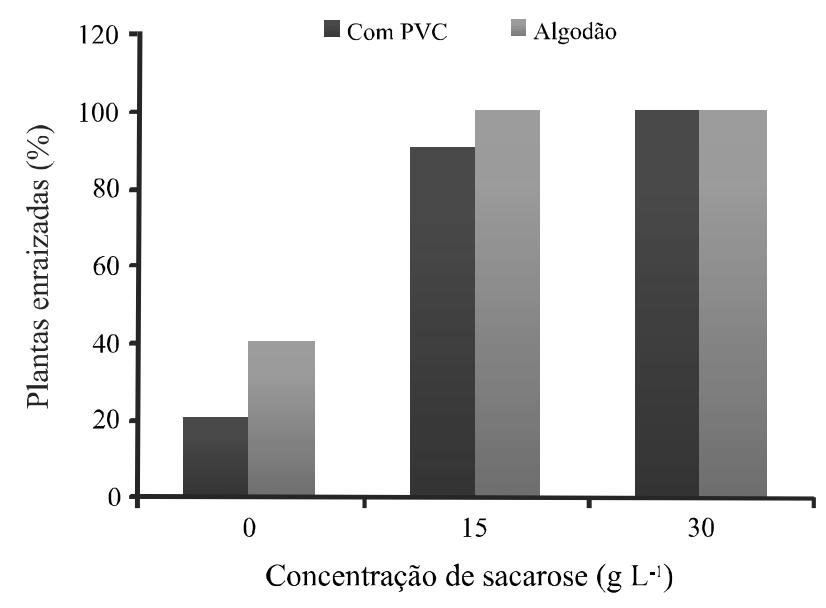


Tabela 1 - Resumo da análise de variância para número de folhas (NF), comprimento $(\mathrm{cm})$ da parte aérea (CPA) e número de raízes (NR) de plantas de caroá após 30 dias de pré-aclimatização in vitro

\begin{tabular}{lcccc}
\hline \multirow{2}{*}{$\mathrm{FV}$} & \multirow{2}{*}{$\mathrm{GL}$} & $\mathrm{N}$ & $\mathrm{C}$ & $\mathrm{CPadrado}$ Médio \\
\cline { 3 - 5 } & & $1,8985^{* *}$ & $9 \mathrm{~cm})$ & $\mathrm{NR}^{1}$ \\
\hline SAC & 2 & $0,8052^{* *}$ & $15,4742^{* *}$ & $21,9145^{* *}$ \\
VED & 1 & $0,0035^{\text {ns }}$ & $1,0051^{\text {ns }}$ & $1,3342^{\text {ns }}$ \\
SAC*VED & 2 & 0,0837 & 1,4401 & $1,2184^{\text {ns }}$ \\
Resíduo & 49 & 10,69 & 25,37 & 0,5696 \\
\hline CV $(\%)$ & & 4,0000 & 4,7309 & 27,41 \\
Média Geral & & & 8,5091 \\
\hline
\end{tabular}

FV - Fontes de variação; SAC - concentração de sacarose; VED - Tipos de vedamento; ${ }^{\text {ns }}$ - não significativo, ${ }^{* *}$ - significativo a $1 \%$ de significância pelo teste F

experimento 1 encontra-se na Tabela 1. A interação entre as concentrações de sacarose e sais do MS não foi significativa para as variáveis estudadas, passando-se a considerar o efeito isolado de cada fator. A sacarose e o vedamento influenciaram de forma significativa todas as variáveis estudadas $(\mathrm{p}<0,01)$, com exceção do número de raízes que não apresentou resultados significativos em resposta ao tipo de vedação (Tabela 1).

Considerando os efeitos dos fatores isoladamente, a presença da sacarose no meio de cultura proporcionou resultados melhores para todas as variáveis avaliadas, ainda que não tenha sido observado diferença significativa entre as duas concentrações utilizadas (Tabela 2). A sacarose é indispensável na etapa de pré-aclimatização, pois esse carboidrato favorece o desenvolvimento da planta in vitro para suprir suas necessidades metabólicas, quer participando na geração de energia ou como fonte de esqueletos carbônicos para vários processos biossintéticos implicados na diferenciação e crescimento celular (LEIFERT et al., 1995). Vários autores mencionam que a sacarose é importante para a formação de um sistema radicular in vitro consistente e funcional, sendo importante para a sobrevivência das plantas na fase de aclimatização (CALVETE; KAMPF; SUZIN, 2002; ERIG; SCHUCH; HAVES, 2004; LEITE; FINARDI; FORTES, 2000).

No que se refere aos tipos de vedação avaliados, os melhores resultados foram obtidos comotampão de algodão para as variáveis número de folhas (NF) e comprimento (cm) da parte aérea (CPA), com um ganho em torno de 30 a 40\% (Tabela 2). Já para a variável número de raízes (NR) esse fator não influenciou significativamente (Tabela 1) por isso as médias obtidas, 7,17 (PVC) e 10,12 (Algodão), não apresentaram diferença estatística (Tabela 2). A vedação com tampão de algodão nos tubos de ensaio, provavelmente, permitiu maiores trocas gasosas influenciando de forma positiva o crescimento das plantas. Resultado similar foi obtido por Santana et al. (2008) que obtiveram melhores taxas de enraizamento in vitro de brotos de Annona glabra L. em meio de cultura sem a presença de sacarose, porém com tubos vedados com tampão de algodão e com tampa plástica sem a película de PVC. Já Cuzzuol et al. (1995) ao propagar in vitro o cravo (Dianthu\s caryophyllus L.) comparou tampão de algodão com o vedamento com papel alumínio, sendo os melhores resultados obtidos com

Tabela 2 - Valores médios do número de folhas (NF), comprimento (cm) da parte aérea (CPA), número de raízes (NR) de plantas de caroá após 30 dias de pré-aclimatização in vitro

\begin{tabular}{|c|c|c|c|}
\hline Sacarose $\left(\mathrm{g} \mathrm{L}^{-1}\right)$ & NF & $\mathrm{CPA}(\mathrm{cm})$ & NR \\
\hline 0 & $4,75 \mathrm{~b}$ & $1,66 \mathrm{~b}$ & $2,13 b$ \\
\hline 15 & $7,68 \mathrm{a}$ & $6,38 \mathrm{a}$ & $12,00 \mathrm{a}$ \\
\hline 30 & $8,15 \mathrm{a}$ & $5,62 \mathrm{a}$ & $10,30 \mathrm{a}$ \\
\hline Tipos de Vedamento & $\mathrm{NF}$ & $\mathrm{CPA}(\mathrm{cm})$ & $\mathrm{NR}$ \\
\hline PVC & $6,23 \mathrm{~b}$ & $4,10 \mathrm{~b}$ & 7,17 a \\
\hline Algodão & $7,92 \mathrm{a}$ & $5,49 \mathrm{a}$ & $10,12 \mathrm{a}$ \\
\hline
\end{tabular}

Médias seguidas pela mesma letra em cada variável não diferem significativamente entre si pelo teste de Tukey a 5\% de significância 
o uso do algodão. Outros estudos realizados nesta direção corroboram a necessidade de se utilizar estratégias que permitam a troca entre o ambiente interno do frasco e o meio externo (CHANDRA et al., 2010; JACKSON, 2003).

Os resultados da taxa de enraizamento para o segundo experimento (concentrações de sacarose e sais do MS) encontram-se na Figura 2. Houve variação de 20 a $100 \%$ de enraizamento, sendo que na ausência de sacarose os efeitos das concentrações dos sais de MS apareceram de forma mais marcante. A menor taxa de enraizamento foi observada na ausência de fonte de carbono com a concentração original do meio MS. À medida que se reduziu os sais do MS na ausência da sacarose registrou-se um aumento nessa taxa. Já nas concentrações de 15 e $30 \mathrm{~g} \mathrm{~L}^{-1}$ de sacarose as diferenças observadas foram mais discretas.

Figura 2 - Enraizamento in vitro (\%) de plantas micropropagadas de caroá [N. variegata (Arruda) Mez] vedadas com tampas de algodão após 30 dias de pré-aclimatização in vitro

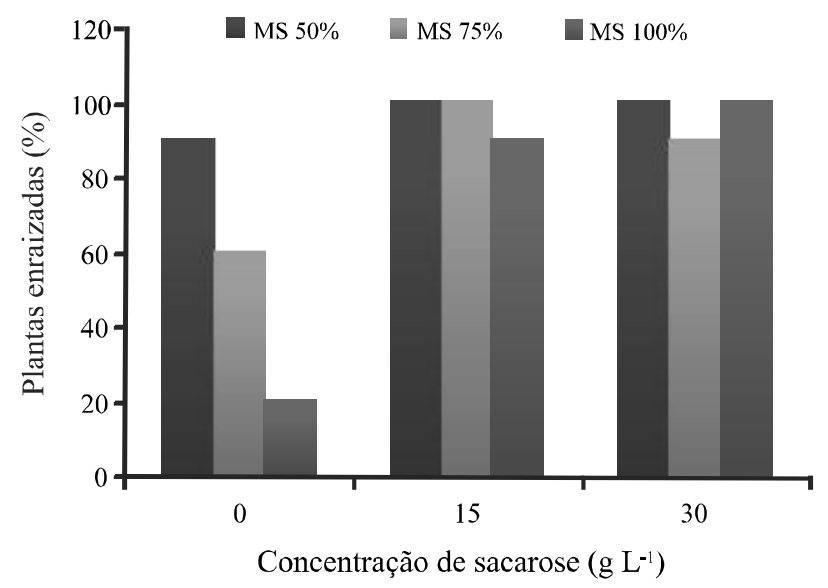

Estes resultados estão de acordo com outros trabalhos os quais são destacados os efeitos positivos da redução dos sais de MS na melhoria do enraizamento de plantas in vitro (ERIG; SCHUCH; HAVES 2004; LEITZKE; DAMIANI; SCHUCH, 2009). A elevada concentração de sais (macro e micronutrientes) do meio MS torna-se prejudicial ao enraizamento de brotos em algumas espécies, havendo necessidade de diluições das formulações básicas (50 ou a 75\%) para o melhor enraizamento in vitro (ERIG; SCHUCH; HAVES, 2004).

Conforme se observa na Tabela 3 os resultados da análise de variância para o experimento 2 mostraram um efeito significativo da interação entre as concentrações de sacarose e dos sais do MS $(\mathrm{p}<0,01)$ para as variáveis, número de folhas $(\mathrm{NF})$ e comprimento $(\mathrm{cm})$ da parte aérea (CPA). Para a variável número de raízes (NR) a interação não foi significativa ainda que os fatores isoladamente tenham influenciado nas respostas obtidas.

O maior número de folhas $(9,00)$ foi observado nos tratamentos com a mais elevada concentração de sais do MS em combinação com 15 e $30 \mathrm{~g} \mathrm{~L}^{-1}$ de sacarose (Tabela 4). Ribeiro et al. (2007) cultivando in vitro o manjericão (Ocimum basilicum L.) obtiveram o maior número de folhas quando adicionou sacarose nas concentrações de 2 ou $3 \%$ em meio MS com concentração total dos sais, resultado similar ao que foi encontrado neste trabalho com o caroá. Em outro trabalho sobre multiplicação in vitro da amoreira-preta, realizado por Villa et al. (2005) o número de folhas foi igualmente estimulado pelo aumento da concentração de sais de MS. Já Villa et al. (2006) micropropagando o porta-enxerto de videira obtiveram a melhor resposta dessa variável com metade do meio MS, adicionado de $30 \mathrm{~g} \mathrm{~L}^{-1}$ de sacarose. Os trabalhos mencionados acima destacam a importância dos sais do MS para o bom desenvolvimento foliar de plantas in vitro para várias espécies.

Tabela 3 - Resumo da análise de variância para número de folhas (NF), comprimento $(\mathrm{cm})$ da parte aérea (CPA) e número de raízes (NR) de plantas de caroá vedadas com tampas de algodão após 30 dias de pré-aclimatização in vitro

\begin{tabular}{lcccc}
\hline \multirow{2}{*}{ FV } & \multirow{2}{*}{ GL } & \multicolumn{3}{c}{ Quadrado Médio } \\
\cline { 3 - 5 } & & $\mathrm{NF}$ & $\mathrm{CPA}(\mathrm{cm})$ & $\mathrm{NR}$ \\
\hline SAC & 2 & $1,1935^{* *}$ & $50,4836^{* *}$ & $16,4532^{* * *}$ \\
SAIS & 2 & $1,7160^{* *}$ & $0,7214^{\mathrm{ns}}$ & $2,7807^{\text {ns }}$ \\
SAC*SAIS & 4 & $0,3064^{* *}$ & $4,7130^{*}$ & $1,1573^{\text {ns }}$ \\
Resíduo & 75 & 0,0801 & 1,4913 & 0,6241 \\
\hline CV $(\%)$ & & 10,98 & 23,85 & 24,21 \\
Média Geral & & 6,2976 & 5,1202 & 11,2024 \\
\hline
\end{tabular}

FV - Fontes de variação; SAC - concentrações de sacarose; SAIS - concentração de sais do MS; ns - não significativo, ** e * - significativo a $1 \%$ e $5 \%$ de significância pelo teste F, respectivamente 
Tabela 4 - Valores médios para número de folhas (NF) e comprimento (cm) da parte aérea (CPA) de plantas de caroá vedadas com tampas de algodão após 30 dias de pré-aclimatização in vitro

\begin{tabular}{|c|c|c|c|}
\hline \multicolumn{4}{|c|}{$\mathrm{NF}$} \\
\hline \multirow{2}{*}{ Sais do MS (\%) } & \multicolumn{3}{|c|}{ Sacarose $\left(\mathrm{g} \mathrm{L}^{-1}\right)$} \\
\hline & 0 & 15 & 30 \\
\hline 50 & $5,09 \mathrm{aB}$ & $4,82 \mathrm{bB}$ & $7,27 \mathrm{bA}$ \\
\hline 75 & $4,83 \mathrm{aA}$ & $5,40 \mathrm{bA}$ & $5,33 \mathrm{cA}$ \\
\hline 100 & $5,67 \mathrm{aB}$ & $8,44 \mathrm{aA}$ & $9,00 \mathrm{aA}$ \\
\hline \multicolumn{4}{|c|}{$\mathrm{CPA}$} \\
\hline \multirow{2}{*}{ Sais do MS (\%) } & \multicolumn{3}{|c|}{ Sacarose $\left(\mathrm{g} \mathrm{L}^{-1}\right)$} \\
\hline & 0 & 15 & 30 \\
\hline 50 & $3,58 \mathrm{aB}$ & $6,30 \mathrm{abA}$ & $4,55 \mathrm{bB}$ \\
\hline 75 & $3,98 \mathrm{aB}$ & $5,65 \mathrm{bA}$ & $5,63 \mathrm{abA}$ \\
\hline 100 & $2,68 \mathrm{aC}$ & $6,82 \mathrm{aA}$ & $5,71 \mathrm{aB}$ \\
\hline
\end{tabular}

Médias seguidas pela mesma letra minúscula dentro das colunas e maiúscula nas linhas não diferem significativamente entre si pelo teste de Tukey a $5 \%$ de significância

Na Tabela 4 observa-se que os tratamentos com $15 \mathrm{~g} \mathrm{~L}^{-1}$ de sacarose em combinação com 50 e $100 \%$ dos sais do MS apresentaram os melhores resultados para o comprimento da parte aérea, 6,30 e $6,82 \mathrm{~cm}$, respectivamente. Por outro lado, os resultados obtidos deixam evidente que a presença de sacarose é crucial para o desenvolvimento da parte aérea, visto que independente das concentrações dos sais do MS, os valores obtidos para essa variável na ausência do açúcar foram os mais baixos. Em trabalhos com gloxínia (Sinningia speciosa Lood. Hiern) realizados por Pereira et al. (2003), o maior comprimento da parte aérea foi obtido no tratamento com $15 \mathrm{~g} \mathrm{~L}^{-1}$ de sacarose e 50\% de sais minerais do MS. Já Naves et al. (2003) trabalhando com outra bromélia (Nidularium fulgens), obtiveram melhores resultados para explantes responsivos com a utilização de $50 \%$ de sais minerais do meio Knudson C.

Tabela 5 - Valores médios do número de raízes (NR) de plantas vedadas com tampas de algodão após 30 dias de préaclimatização in vitro

\begin{tabular}{lc}
\hline Sacarose $\left(\mathrm{g} \mathrm{L}^{-1}\right)$ & $\mathrm{NR}$ \\
\hline 0 & $5,83 \mathrm{~b}$ \\
15 & $14,73 \mathrm{a}$ \\
30 & $11,77 \mathrm{a}$ \\
\hline
\end{tabular}

Médias seguidas pela mesma letra não diferem significativamente entre si pelo teste de Tukey a $5 \%$ de significância
De acordo com a análise de variância não houve interação significativa para o número de raízes (Tabela 3) e apenas a sacarose influenciou nos resultados obtidos, que podem ser observados na Tabela 5. A ausência da fonte de carbono compromete o desenvolvimento, enquanto ambas as concentrações (15 e $30 \mathrm{~g} \mathrm{~L}^{-1}$ ) proporcionaram os melhores resultados independente da concentração dos sais de MS utilizados nos meios de cultura. Em trabalhos com duas cultivares de marmelo, o enraizamento in vitro foi favorecido com a redução dos sais do MS a $75 \%$ e com $15 \mathrm{~g} \mathrm{~L}^{-1}$ de sacarose no meio de cultura, porém os autores não utilizaram tampas de algodão (ERIG; SCHCH; HAVES, 2004).

Os resultados obtidos neste experimento destacaram a necessidade inequívoca de se adicionar sacarose ao meio de cultura, assim como o uso da concentração original dos sais do MS parecem favorecer a formação de biomassa. Outro aspecto que precisa ser destacado foi o uso de tampas de algodão, como sistema de vedação, favorecendo mais as trocas gasosas. Apesar da redução do volume inicial do meio de cultura em 50\%, num período de 30 dias, não foi constatado nenhum tipo de contaminação, fúngica ou bacteriana, deixando evidente a possibilidade de se usar de forma mais constante este tipo de vedação. Essas observações também foram feitas por Nepomuceno et al (2009) ao cultivarem plântulas de Anadenanthera colubrina em tubos fechados com tampão de algodão.

Vários autores mencionam que ao melhorar a aeração dos tubos de ensaio ocorre maior desenvolvimento no enraizamento (LUCCHESINI; MENSUALI-SODI, 2004; SANTANA et al., 2008), além disso, pode proporcionar aumento da biomassa e um sistema radicular extensivo 
quando mantidas em condições para a transferência $e x$ vitro como foi observado nas brotações de Phillyrea por Lucchesini e Mensuali-Sodi (2004). Assim, considerando as variáveis analisadas neste trabalho, as plantas de caroá crescidas em ambiente aerado tiveram melhores resultados quando utilizou a concentração original de sais de MS acrescido de 15 ou $30 \mathrm{~g} \mathrm{~L}^{-1}$ de sacarose no meio de cultura.

Já para o experimento de aclimatização das mudas de caroá observou-se que as plantas aclimatizadas no substrato Plantmax ${ }^{\circledR}$ após 180 dias apresentaram taxa de sobrevivência de 20 a $100 \%$, sendo que as plantas oriundas dos tratamentos que não continham sacarose no meio de cultura apresentaram percentuais mais baixos (Figura 3). Contudo, pode-se verificar também na Figura 3 que as plantas oriundas dos meios que tinham

Figura 3 - Sobrevivência das mudas de caroá [N. variegata (Arruda) Mez] pré-aclimatizadas in vitro após 180 dias de aclimatização em Plantmax ${ }^{\circledR}$

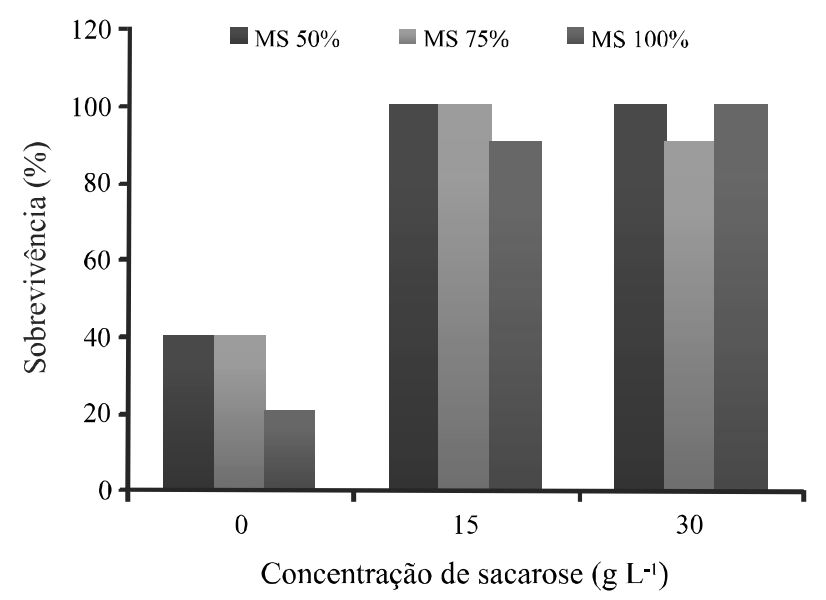

concentrações reduzidas dos sais do MS favoreceram a taxa de sobrevivência. Esses resultados diferem dos encontrados por Augusto et al. (2006) com amoreira-preta, que observaram que não houve diferença na sobrevivência das plantas aclimatizadas originadas dos meios de enraizamento sem e com sacarose $\left(30 \mathrm{~g} \mathrm{~L}^{-1}\right)$ combinados com metade da concentração dos sais de MS.

Na Tabela 6 pode-se observar que a interação entre as concentrações de sacarose e de sais de MS foi significativa $(\mathrm{p}<0,05)$ para as variáveis, número de folhas (NF), matéria seca da parte aérea (MSPA) e matéria seca da raiz (MSR). Para a variável comprimento $(\mathrm{cm})$ da parte aérea $(\mathrm{CPA})$ houve efeito significativo de sacarose $(\mathrm{p}<0,01)$. Não houve efeito significativo $(\mathrm{p}>0,05)$ para número de raízes $(\mathrm{NR})$.

Na Tabela 7 verifica-se que após 180 dias de aclimatização as plantas que foram pré-aclimatizadas nos meios com a concentração original dos sais do MS suplementado com 15 e $30 \mathrm{~g} \mathrm{~L}^{-1}$ de sacarose apresentaram o maior número de folhas, 11,56 e 11,27, respectivamente. Com relação às massas secas da parte aérea (MSPA) e da raiz (MSR), os melhores resultados foram obtidos no meio de pré-aclimatização com as concentrações de 75 e $100 \%$ dos sais do MS e $15 \mathrm{~g} \mathrm{~L}^{-1}$ de sacarose.

No que se refere ao comprimento da parte aérea, o melhor resultado foi obtido no meio de pré-aclimatização com $15 \mathrm{~g} \mathrm{~L}^{-1}$ de sacarose $(8,55 \mathrm{~cm})$ independente das concentrações de sais do MS utilizadas (Tabela 8).

Em relação às raízes, como não houve interação nas fontes de variação o número de raízes não foi influenciado pelas concentrações de sacarose e de sais do MS após 180 dias de aclimatização (Tabela 6). Esse resultado pode ter acontecido pela fragilidade das raízes

Tabela 6 - Resumo da análise de variância para as variáveis número de folhas (NF), comprimento (cm) da parte aérea (CPA), número de raiz (NR), matéria seca da parte aérea (MSPA) e matéria seca da raiz (MSR) (g) de mudas micropropagadas de caroá após 180 dias de pré-aclimatização in vitro

\begin{tabular}{lcccccc}
\hline \multirow{2}{*}{ FV } & \multirow{2}{*}{ GL } & \multicolumn{5}{c}{ Quadrado Médio } \\
\cline { 3 - 7 } & & NF & CPA & NR & MSPA & MSR \\
\hline SAC & 2 & $0,2047^{*}$ & $43,1507^{* *}$ & $0,1802^{\text {ns }}$ & $1,3095^{* *}$ & $0,2096^{* *}$ \\
SAIS & 2 & $0,4762^{* *}$ & $4,4115^{\text {ns }}$ & $0,2175^{\text {ns }}$ & $0,4137^{*}$ & $0,0637^{* *}$ \\
SAC*SAIS & 4 & $0,1441^{*}$ & $0,7894^{\text {ns }}$ & $0,1100^{\text {ns }}$ & $0,3204^{* *}$ & $0,0676^{* *}$ \\
Resíduo & & 0,0416 & 1,6215 & 0,0560 & 0,0783 & 0,0117 \\
\hline CV (\%) & & 6,22 & 17,34 & 8,80 & 31,68 & 35,45 \\
Média Geral & & 10,3239 & 7,3422 & 6,8000 & 0,8835 & 0,3047 \\
\hline
\end{tabular}

FV - Fontes de variação; SAC - concentrações de sacarose; SAIS - concentração de sais do MS; ${ }^{\text {ns }}$ - não significativo, ** e * - significativo a $1 \%$ e $5 \%$ de significância pelo teste $\mathrm{F}$, respectivamente 
Tabela 7 - Valores médios para número de folhas (NF), comprimento $(\mathrm{cm})$ da parte aérea (CPA), matéria seca da parte aérea (MSPA) e matéria seca da raiz (MSR) de mudas micropropagadas de caroá após 180 dias de pré-aclimatização in vitro

\begin{tabular}{|c|c|c|c|c|}
\hline \multicolumn{5}{|c|}{$\mathrm{NF}$} \\
\hline & \multirow{2}{*}{ Sais do MS (\%) } & \multicolumn{3}{|c|}{ Sacarose $\left(\mathrm{g} \mathrm{L}^{-1}\right)$} \\
\hline & & 0 & 15 & 30 \\
\hline 50 & & $8,75 \mathrm{aB}$ & $8,00 \mathrm{bB}$ & $10,27 \mathrm{aA}$ \\
\hline 75 & & $10,25 \mathrm{aA}$ & $10,90 \mathrm{aA}$ & $11,11 \mathrm{aA}$ \\
\hline 100 & & $9,50 \mathrm{aB}$ & $11,56 \mathrm{aA}$ & $11,27 \mathrm{aAB}$ \\
\hline \multicolumn{5}{|c|}{$\operatorname{MSPA}(\mathrm{g})$} \\
\hline \multirow{2}{*}{\multicolumn{2}{|c|}{ Sais do MS (\%) }} & \multicolumn{3}{|c|}{ Sacarose $\left(\mathrm{g} \mathrm{L}^{-1}\right)$} \\
\hline & & 0 & 15 & 30 \\
\hline 50 & & $0,47 \mathrm{aB}$ & $0,63 \mathrm{bB}$ & $0,97 \mathrm{abA}$ \\
\hline 75 & & $0,54 \mathrm{aB}$ & $1,31 \mathrm{aA}$ & $1,21 \mathrm{aA}$ \\
\hline 100 & & $0,24 \mathrm{aC}$ & $1,29 \mathrm{aA}$ & $0,74 \mathrm{bB}$ \\
\hline \multicolumn{5}{|c|}{ MSR (g) } \\
\hline \multirow{2}{*}{\multicolumn{2}{|c|}{ Sais do MS (\%) }} & \multicolumn{3}{|c|}{ Sacarose $\left(\mathrm{g} \mathrm{L}^{-1}\right)$} \\
\hline & & 0 & 15 & 30 \\
\hline 50 & & $0,15 \mathrm{aA}$ & $0,21 \mathrm{bA}$ & $0,28 \mathrm{bA}$ \\
\hline 75 & & $0,16 \mathrm{aB}$ & $0,44 \mathrm{aA}$ & $0,45 \mathrm{aA}$ \\
\hline 100 & & $0,07 \mathrm{aB}$ & $0,54 \mathrm{aA}$ & $0,25 \mathrm{bB}$ \\
\hline
\end{tabular}

Médias seguidas pela mesma letra minúscula dentro das colunas e maiúscula nas linhas não diferem significativamente entre si pelo teste de Tukey a $5 \%$ de significância

Tabela 8 - Valores médios para comprimento da parte aérea (CPA) de mudas micropropagadas de caroá após 180 dias de pré-aclimatização in vitro

\begin{tabular}{lc}
\hline Sacarose $\left(\mathrm{g} \mathrm{L}^{-1}\right)$ & CPA $(\mathrm{cm})$ \\
\hline 0 & $5,54 \mathrm{c}$ \\
15 & $8,55 \mathrm{a}$ \\
30 & $6,76 \mathrm{~b}$ \\
\hline
\end{tabular}

Médias seguidas pela mesma letra minúscula não diferem significativamente entre si pelo teste de Tukey a $5 \%$ de significância

in vitro que se soltam durante o plantio. Por outro lado, a prática de cortar as raízes velhas (produzidas in vitro) e pouco funcionais antes da aclimatização de plantas de bromélias e de abacaxi é recomendado a fim de estimular a produção de novas raízes (SOUZA et al., 2009), o que não foi feito neste trabalho. Silveira $e t$ al. (2010) sugerem que uma vez iniciada a rizogênese in vitro, pode ocorrer o favorecimento do crescimento das plantas na fase de aclimatização, pela renovação desse sistema radicular.
O que vale destacar é que o comportamento observado para as variáveis de crescimento (número de folhas, comprimento da parte aérea e número de raízes) no experimento 2 foi o mesmo na aclimatização, confirmando que pode ser realizado um procedimento de pré-aclimatização que favoreça a transição das plantas in vitro para a condição ex vitro, reduzindo as perdas e melhorando o desenvolvimento das plantas. Com esse procedimento (pré-aclimatização + aclimatização) totalizou-se 210 dias, tendo os resultados destas variáveis aos 180 dias de aclimatização superiores aos obtidos por Silveira et al. (2010) que aclimatizaram diretamente plantas de caroá em diferentes substratos durante 210 dias sem passar pela etapa da préaclimatização in vitro.

\section{CONCLUSÕES}

1. O uso de tampas de algodão e a adição de sacarose favorece maiores trocas gasosas e o crescimento, influenciando no desenvolvimento in vitro de plantas de caroá; 
2. As concentrações de 15 e $30 \mathrm{~g} \mathrm{~L}^{-1}$ de sacarose combinados com a concentração original do meio MS proporcionam melhor desenvolvimento na préaclimatização in vitro de plantas de caroá;

3. A pré-aclimatização de plantas de caroá favorece melhor crescimento das plantas na etapa de aclimatização e reduz o período de aclimatização de mudas de caroá.

\section{REFERÊNCIAS}

AUGUSTO, C. S. S. et al. Enraizamento e aclimatização de plantas micropropagadas de amoreira-preta cv. Brazos. Revista Brasileira de Fruticultura, v. 28, n. 3, p. 473-476, 2006.

CALVETE, E. O.; KÄMPF, A. N.; SUZIN, M. Concentração de sacarose no enraizamento in vitro de morangueiro. Horticultura Brasileira, v. 20, n. 2, p. 186-191, 2002.

CHANDRA, S. et al. Acclimatization of tissue cultured plantlets: from laboratory to land. Biotechnol Lett, v. 32, n. 9, p. 1199-1205, 2010.

CUZZUOL, G. R. F. et al. Controle da vitrificação do cravo (Dianthus caryophyllus L.). Scientia Agricola, v. 52, n. 3, p. 604-614, 1995.

ERIG, A.C.; SCHUCH, M.W.; HAVES, A. da C. Enraizamento in vitro e aclimatização de mudas de marmeleiro cvs. MC e Adams, utilizadas como porta-enxerto para a pereira. Scientia Agraria, v. 5, n. 1/2, p. 61-68, 2004.

HARARIKA, B. N. Acclimatization of tissue-cultured plants. Current Science, v. 85, n. 12, p. 1704-1712, 2003.

HOFFMANN, A. et al. Efeito de substratos na aclimatização de plantas micropropagadas do porta-enxerto de macieira 'Marubakaido. Ciência e Agrotecnologia, v. 25, n. 2, p. 462467, 2001.

JACKSON, M. B. Aeration stress in plant tissue cultures. Bulgarian Journal of Plant Physiology, Special issue, p. 96-109, 2003.

LEIFERT, C. et al. Mineral and carbohydrate nutrition of plant cell and tissue cultures. Critical Reviews in Plant Sciences, v. 14, n. 2, p. 83-109, 1995.

LEITE, G. B.; FINARDI, N.; FORTES, G. R. L. Efeitos de concentrações de sacarose no meio de cultura e da intensidade luminosa no enraizamento "in vitro" do porta-enxerto de pereira OH X F971. Ciência Agrotecnologia, v. 24, n. 2, p. 353-357, 2000.

LEITZKE, L. N.; DAMIANI, C. R.; SCHUCH, M. W. Multiplicação e enraizamento in vitro de amoreira-preta 'Xavante': efeito da concentração de sais, do tipo de explante e de carvão ativado no meio de cultura. Ciência Agrotecnologia, v. 33, p. 1959-1966, 2009. Edição especial.
LUCCHESINI, M.; MENSUALI-SODI, A. Influence of medium composition and vessel entilation on in vitro of Phillyrea latifolia L. Scientia Horticulturae, v. 100, n. 1/4, p. 117-125, 2004.

MURASHIGE, T.; SKOOG, F. A revised medium for rapid growth and bio assays with tobacco tissue cultures. Physiologia Plantarum, v. 15, n. 3, p. 473-497, 1962.

NAVES, V. C. et al. Avaliações de diferentes concentrações dos meios de cultura MS e Knudson C para a propagação in vitro de Nidularium Fulgens Lam. In: CONGRESSO BRASILEIRO DE FLORICULTURA E PLANTAS ORNAMENTAIS, 14., 2003, Lavras. Anais... Lavras: UFLA, 2003. p. 229.

NEPOMUCENO, C. F. et al. Respostas morfofisiológicas in vitro de plântulas de Anadenanthera colubrina (Vell.) Brenan var. cebil (Griseb) Altschul, Revista Árvore, v. 33, n. 3, p. 481-490, 2009.

OLIVEIRA, Y. de et al. Pré-aclimatização in vitro de abacaxi ornamental. Ciência e Agrotecnologia, v. 34, p. 1647-1653, 2010. Número especial.

PEREIRA, A. R. et al. Concentrações do meio de cultura e sacarose no crescimento in vitro de gloxínia. In: CONGRESSO BRASILEIRO DE FLORICULTURA E PLANTAS ORNAMENTAIS, 14., 2003, Lavras. Anais... Lavras: UFLA, 2003. p. 260.

POMPELLI, M. F.; FERNANDES, D.; GUERRA, M. P. Somatic embryogenesis in Dyckia distachya Hassler (Bromeliaceae) - an endangered bromeliad from South Brazil. Propagation of Ornamental Plants, v. 5, n. 4, p. 192-198, 2005.

POMPELLI, M. F.; GUERRA, M. P. Ex situ conservation of Dyckia distachya: an endangered bromeliad from South Brazil. Crop Breeding and Applied Biotechnology, v. 4, n. 4, p. 273-279, 2004.

RIBEIRO, M. de N. O. et al. Diferentes concentrações de sais do meio MS e de sacarose na multiplicação in vitro de Zantedeschia aethiopica L. Spreng. (copo-deleite). Revista Ciência Agronômica, v. 39, n. 1, p. 101-106, 2008.

RIBEIRO, M. F. et al. Influência de diferentes concentrações de sais de MS e açúcares no cultivo in vitro de manjericão roxo (Ocimum basilicum L.). Revista Brasileira de Biociências, v. 5, p. 57-59, 2007. Suplemento 2.

SANTANA, J. R. F. et al. Estímulo do comportamento fotoautotrófico durante o enraizamento in vitro de Annona glabra L., I. Desenvolvimento do sistema radicular e da parte aérea. Ciência Agrotecnologia, v. 32, n. 1, p. 80-86, 2008.

SILVA, J. A. T. da et al. Effect of physical factors on micropropagation of Anthurium andreanum. Plant Tissue Culture, v. 15, n. 1, p. 1-6, 2005.

SILVEIRA, D. G. et al. Development of micropropagated shoots and plants of Caroa in different substrates. Acta Horticulturae, v. 865, p. 305-313, 2010.

SILVEIRA, D. G. et al. Variabilidade genética de populações naturais de caroá por meio de marcadores RAPD. Pesquisa Agropecuária Brasileira, v. 44, n. 3, p. 283-290, 2009a. 
SILVEIRA, D. G. et al. Micropropagation and in vitro conservation of Neoglaziovia variegata (Arr. Cam.) Mez, a fiber producted bromeliad from Brazil. Brazilian Archives of Biology and Technology, v. 52, n. 4, p. 923-932, 2009b.

SOUZA, F. V. D. et al. Aclimatização. In: SOUZA, A. da S.; JUNGHANS, T. G. Introdução à micropropagação de plantas. Cruz das Almas: Embrapa Mandioca e Fruticultura Tropical, 2006. p. 131-140.

SOUZA, F. V. D. et al. Micropropagação do abacaxizeiro e outras bromeliaáceas.In: JUNGHANS, T. G.; SOUZA, A. da
S. Aspectos práticos da micropropagação de plantas. Cruz das Almas: Embrapa Mandioca e Fruticultura Tropical, 2009. p. 177-205.

VILLA, F. et al. Multiplicação in vitro da amoreira-preta 'Ébano' em diferentes concentrações de meio MS e BAP. Ciência Agrotecnologia, v. 29, p. 582-589, 2005.

VILLA, F. et al. Multiplicação in vitro de porta-enxerto de videira em variações do meio MS. Acta Scientiarum Agronomy, v. 28, n. 3, p. 345-349, 2006. 